\title{
[CH] Securing a conducive environment for WASH markets: The role of local government
}

Anna Gero, BEnvSc (Hons), MDev. Institute for Sustainable Futures, University of Technology Sydney. Juliet Willetts, ${ }^{1}$ BSc(Hons), BE, PhD (Environmental Engineering). Institute for Sustainable Futures, University of Technology Sydney.

[ABS] Local governments play critical, yet under-recognised, roles in supporting or constraining the development of emerging water, sanitation, and hygiene (WASH) markets. The focus of market approaches to date has been primarily on small-scale businesses and social enterprises themselves, rather than on addressing the broader institutional environment.

This study, drawing on experiences in Vietnam, Cambodia, and Indonesia, examined the political economy affecting support to WASH market actors, including the perspective and role of local governments. Semi-structured interviews were conducted with rural water supply enterprises and sanitation entrepreneurs, non-governmental organizations, and government officials. Qualitative analysis yielded key themes as regards political economy dynamics and identification of a breadth of pertinent roles for local governments. This study formed part of a larger research initiative funded through the Australian aid programme, focused on small-scale enterprise and led by the University of Technology Sydney.

The findings demonstrate important local government roles, including: training and business development support to enterprises; linking demand and supply by promoting local enterprises; supporting associations of entrepreneurs; providing targeted subsidies or financing to catalyse private sector engagement or to facilitate access for the poor and disadvantaged; and setting and monitoring quality standards and accreditation of products and services. In particular, balancing an enabling or supporting role with the need to ensure appropriate regulatory functions are in place, provided a point of tension (and sometimes confusion) for local governments. Key motivators driving local government engagement with enterprises included coverage targets. Various constraints limited their support, including lack of clarity on their role, availability of relevant skills, and perceptions that WASH market systems and private sector engagement should arise spontaneously.

These findings inform gaps in development agency programming when it comes to WASH markets, in terms of the need to work more strategically with local government actors, rather than solely directing efforts towards enterprises themselves. This study suggests a way forward in progressing more systemic interventions to support WASH markets, in ways that facilitate local governments and related stakeholders to play more effective roles, and achieve greater and more equitable development outcomes. 


\section{[A]Introduction}

\section{[B]Emerging enterprise roles in WASH}

Private sector involvement in the water, sanitation, and hygiene (WASH) sector has grown over time for four main reasons. Firstly, the 1980s and ' 90 s saw a global shift towards privatization of public assets and market-based approaches in the delivery of public services, an approach formalized by the Washington Consensus development policy (Murthy, 2013). Secondly, public resources were proving inadequate in meeting the needs for WASH services. Thus, the trend towards privatization was supported by the notion that the private sector had expertise and financial resources from which the WASH sector could benefit (Davis, 2005). Governments (at both national and subnational levels) and utilities in many countries therefore viewed the idea of private sector participation in the provision of WASH favourably, given the challenges they faced in providing such services efficiently (Murthy, 2013) and their inability to meet existing needs. This is particularly important given the significant number of people in the world who live without adequate water and sanitation - a billion people practise open defecation and 768 million use unimproved sources of drinking water (Sy et al., 2014). Thirdly, both the Sustainable Development Goal (SDG) 6 ('Ensure availability and sustainable management of water and sanitation for all') and the human right to water and sanitation (recognized under the United Nations General Assembly Resolution 64/292) provide ongoing impetus for governments to ensure the needs of the poor and marginalized are met. Governments are obliged to provide the conditions for these needs to be met - and this may include conditions conducive to private sector involvement (discussed in more detail below). Lastly, the reliance on voluntary community management models for water supply has been called in to question (Whaley and Cleaver, 2017) and, similarly for sanitation, skills and capacities beyond community capacity (for instance quality products that can enhance usage and sustainability) are increasingly being recognized as important (Devine and Kullman, 2011). Introducing professionalized models of produce and service provision through private (or social) enterprises has been proposed as a means to evolve current approaches. These four drivers provide a strong push for the private sector to play a role in delivering WASH services in a range of contexts.

Given the growing demands for WASH services globally and the existing populations with unmet water and sanitation needs, private sector operators are now seen as key players in the solution to WASH service provision for the poor (Gero et al., 2014; Sy et al., 2014). Development agencies are increasingly looking to engage with private sector actors, WASH markets, and policy makers but require a strengthened evidence base on which to develop strategic and well-targeted programmes. The focus of this paper is to explore the roles local governments can and should play to enable private sector participation in WASH service delivery in South East Asia. We draw on research undertaken in Indonesia, Vietnam, and Cambodia to illustrate the various ways local governments have become engaged with small-scale WASH enterprises. Firstly, however, the remainder of this introduction sets the scene and describes the nature of enterprises emerging in small-scale WASH provision from the literature. We also describe the types of roles governments play in facilitating WASH markets. Section two outlines the methods for the research, followed by results, implications, and conclusions and recommendations.

\section{[B]Nature of the enterprises}

Small-scale water and sanitation enterprises come in a range of forms and play a diverse range of roles. These include producers and sellers of hardware (both wholesale and retail), franchises, network models, and one-stop shops (Gero et al., 2014). Enterprises also perform service provision roles that can be formal (in a public-private partnership or operating under licence) or informal, for example small piped-network providers, pushcart water deliverers, or water kiosk operators in the water sector, or vacuum truck owners, pump operators, or masons in the sanitation sector (Gero et al., 2014). A useful summary of specialized private and social enterprise roles in rural contexts in Indonesia, Vietnam, and Timor Leste is presented in Willetts et al. (2015). Similarly, Mason et al., 
(2015: 2) describe the diversity as occurring: 'across scales, from sole trader to multinational; across degrees of formality and informality; as well across a spectrum of profit orientation, from social enterprises to fully for-profit companies.'

The business models adopted by small-scale WASH enterprises are also diverse. Sy et al. (2014) describe the links between business models and the government's involvement, whereby the enabling environment can either incentivise or constrain business operations. The questions of how revenue is generated, how tariffs and pricing are set, and how assets are optimized in the water sector rely on the degree of government intervention and support (Sy et al., 2014). Governments, including at the subnational level, therefore play an important role in facilitating WASH markets. This is discussed further in the next section.

\section{[B]Local government roles in facilitating markets}

Governments at national and subnational levels are implicated in facilitating WASH markets for a number of reasons, which are described below along with some of the barriers local governments face in supporting private enterprises in WASH.

Human right to water and sanitation: Governments are responsible and obligated to ensure citizens have access to safe, clean, accessible, and affordable drinking water under the human right to water and sanitation (HRTWS - United Nations Resolution 64/292, 2010). While previously regarded as an implicit responsibility under rights to health and development, the HRTWS was formally adopted in 2010 , and as per other human rights, holds duty-bearers (i.e. governments) to account to ensure the fulfilment of these rights. Actions to meet the HRTWS are interlinked with those for meeting SDG 6, for which the state is also responsible. The private sector also has a role to play in realizing universal access to water and sanitation, and governments must facilitate the engagement of businesses to do so (Gero et al., 2014; Mason et al., 2015).

While the state has obligations to ensure the HRTWS, it is not necessarily required to meet these needs through direct government service provision. Rather, it is the government's responsibility to ensure an enabling environment such that non-state actors (including the private sector) can participate in realizing the rights of citizens (Bos et al., 2016). Conditions necessary to enable these rights may include appropriate institutional arrangements, a legal framework, public awareness campaigns, and monitoring of human rights systems (Bos et al., 2016). However, delegation of water and sanitation operations to the private sector does not equate to the delegation of responsibilities regarding the HRTWS: this responsibility remains with the state (Murthy, 2013). Local governments also face challenges to ensuring the HRTWS in their engagement with the private sector. From a rights perspective, subnational governments are unclear in how to ensure the HRTWS is applied in practice at the local level, while some operators admit to feeling the HRTWS is irrelevant to their work (Bos et al., 2016).

Supportive and mutually beneficial government regulation: Appropriate and fit-for-purpose government regulation can support and incentivize an effective private WASH sector, rather than being seen as a hindrance to private operators. Governments can develop and implement enforceable legal and regulatory frameworks surrounding private sector participation that support the progressive realization of rights (Bos et al., 2016). Such a framework should include both regulation and monitoring, and can effectively address the real or perceived tensions that exist around market-based approaches and human rights (Murthy, 2013).

Opportunities and challenges exist around government regulation for market-based approaches to WASH. In terms of opportunities, legal reforms provide the means to incorporate informal service providers under new regulatory frameworks (Bos et al., 2016). If done effectively, this extends the 
opportunities for informal operators. Policy makers are becoming increasingly aware of the potential role small-scale private WASH operators can play in addressing unmet needs and gaps in service delivery (Mason et al., 2015). Policy frameworks can therefore be developed with private sector input to ensure mutually beneficial outcomes, including addressing barriers faced (particularly from small-scale operators) such as high registration and licensing costs (Mason et al., 2015). Challenges governments face in regulating market-based approaches to WASH include the fact that strong institutional and regulatory capacity is required to ensure arrangements with private operators prioritize public interests (Murthy, 2013). Furthermore, the rights-based approach requires the state to monitor private operators, and in cases of limited resources and capacity, or corruption, this is unlikely to occur (Murthy, 2013). Lastly, the question of public subsidies and how they may impede market demand represents a regulatory challenge (Sy et al., 2014), although studies to date show varied results in this regard, and careful design can avert such effects (Willetts and Powell, 2017).

Barriers faced by local governments to working with private sector operators: In addition to the challenges discussed above regarding regulation, local governments in particular face specific barriers to supporting private sector involvement in WASH. Firstly, there can exist a lack of trust and an absence of relationship between local government and private operators. This presents a barrier to local government and businesses working together. For example, Mason et al. (2015) note instances of small-scale informal sanitation operators reporting distrust of government, presenting a disincentive to obtain legal business registration.

Secondly, as mentioned above, local government may lack the capacity to support and regulate private sector involvement. Specific skills are required in drafting tenders, selecting candidates, and managing contracts, lack of which leaves local government with defective processes and a low quality of work (Sy et al., 2014). From the private sector perspective, low local government capacity means inconsistent administration and delays in contracts, which affect profitability. Adequate capacity within local government therefore matters for both the government and private sector.

A third barrier faced by local governments is the lack of guidance on how to develop local policy to engage with the private sector, and how to implement national policy at the local level. National water and sanitation plans may include goals and targets, including an emphasis on engaging market-based approaches to WASH, but lack the necessary guidance on how such approaches are operationalized at the local level (Mason et al., 2015).

Note that the above local government roles and barriers are drawn from the existing literature: our research identified further roles and barriers, which are described below, along with potential solutions to help overcome them. The next section describes the methods used in our empirical research.

\section{[A]Methods}

We drew upon a political economy analysis framework (Harris 2013, Ostrom, 2011) to underpin our research methodology. Macro-level political economy and the recent history of each country was considered. We examined the water and sanitation sectors and the incentives at play through existing formal and informal rules, both within and between organizations. Utilizing a politicaleconomy-analysis lens we also explored issues of power, control over choice, and access to information, paying particular attention to the roles local government actors play in enterprise engagement. We explored WASH-sector-level dynamics and organization dynamics, focusing on government, private and social enterprises, and the non-government organizations (NGOs) who support private sector participation in WASH. 
Empirical qualitative research was conducted between 2014 and 2016 in Vietnam and Indonesia and in 2016-2017 in Cambodia. These countries were selected as this research formed part of a largescale research project funded by the Australian Development Research Award Scheme (ADRAS) and our partnering NGOs were active in private sector WASH engagement in these countries. Existing outputs from the broader research include examination of incentives for private sector engagement in Indonesia (Murta and Willetts, 2014) and Vietnam (Gero and Willetts, 2014); value chain analysis in low-density settings in Indonesia and Vietnam (Willetts et al., 2017) and traits, drivers, and barriers affecting water and sanitation enterprise roles in Indonesia and Vietnam (Willetts et al., 2016).

Using semi-structured interviews, we engaged stakeholders from government agencies at national and subnational levels, private and social enterprises, local and international NGOs, and donors. (Note that we define local government as the administrative side of government rather than the elected officials and for this research we were only able to interview the former group). In Indonesia, we conducted interviews with representatives from 29 organizations in Jakarta, Central, and East Java, including eight local government representatives. In Vietnam, we conducted interviews with 44 organizations, including 22 local government representatives across the Mekong, central, and northern Vietnam. In Cambodia, the research was informed by a smaller sample of key sanitation sector stakeholders (eight interviews with government and development agency representatives), an in-country facilitated stakeholder workshop (14 participants), and interviews with sanitation entrepreneurs (seven enterprises). In all countries, subnational locations were selected based on the activities of NGO partners. The total breakdown of interviewees participating in the research across the three countries is presented in Table 1.

[CAP]Table 1: Interviewee numbers participating in the research

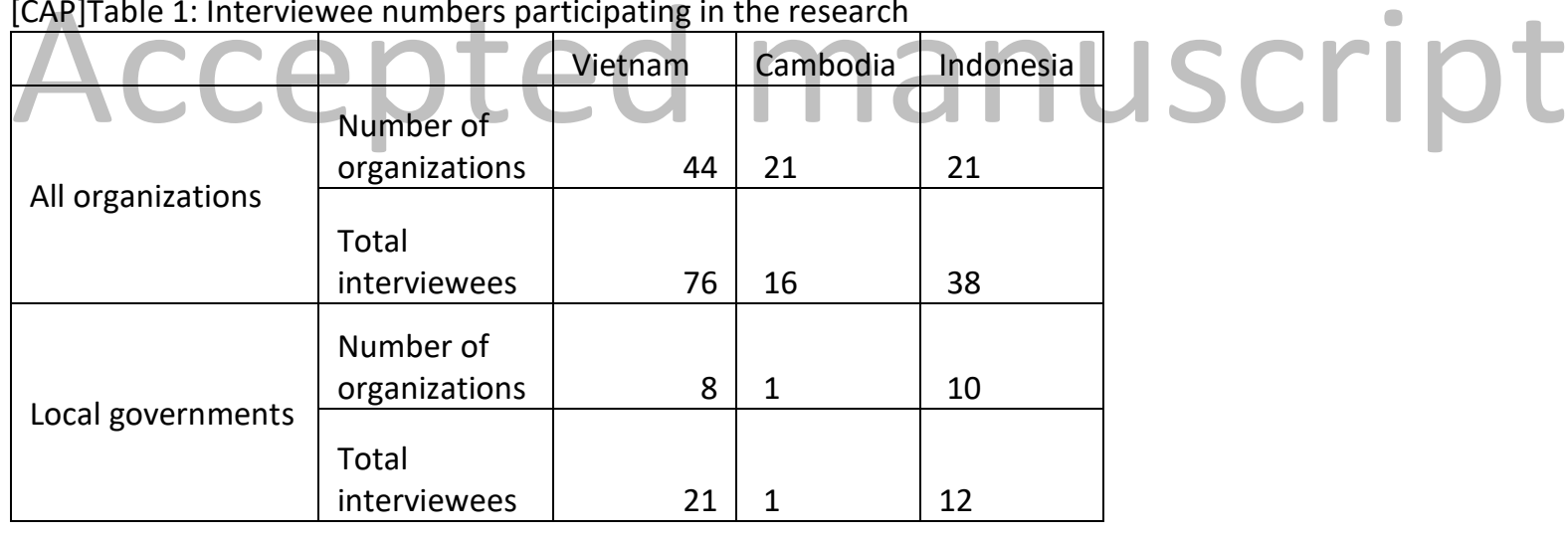

Qualitative analysis was conducted using primary data, coupled with analysis of WASH and private sector policy and other relevant literature to explore the ways in which local governments engage small-scale enterprises, and the challenges they face. The research was conducted in accordance with the researchers' University Code of Ethical Research Conduct. This involved obtaining ethics approval prior to data collection, and consideration of informed consent, translation, privacy, and data storage issues. We worked with local partners in each country and ensured that approaches to engagement with stakeholders were respectful and culturally appropriate.

\section{[A]Findings}

Our research revealed six distinct roles relevant to local government in relation to small-scale WASH enterprises. These were: 1 ) providing training and business development support to enterprises; 2 ) linking demand and supply by promoting local enterprises; 3 ) supporting associations of entrepreneurs; 4) providing targeted subsidies or financing to catalyse private sector engagement or to facilitate access for the poor and disadvantaged; 5) setting and monitoring quality standards and 
accreditation of products and services; and 6) developing appropriate local policy to support enterprise engagement. These roles are discussed below, with evidence provided across Indonesia, Vietnam, and Cambodia. In this section we also discuss the challenges and constraints local governments face in supporting private WASH enterprises.

\section{$[\mathrm{B}]$ Training and business development support to enterprises}

Our research revealed that local government were already active across a range of typical business development support functions relevant to small-scale WASH enterprises. Table 2 describes these roles, and provides examples from our research where local governments were active. This shows that despite the emerging nature of small-scale WASH enterprises in these three countries, local governments had already made efforts to promote and support them. We also outline some of the challenges local governments faced in further offering their support to these businesses.

[CAP]Table 2: Business development support functions and roles played by local governments

\begin{tabular}{|c|c|}
\hline Support function & Examples of local government activity \\
\hline Access to market/ demand creation & $\begin{array}{l}\text { - Local government representatives acting as sales agents for } \\
\text { local small-scale enterprise (Cambodia, Vietnam) } \\
\text { - Local government creating demand, facilitating behaviour- } \\
\text { change, and promoting sanitation, thereby increasing } \\
\text { customer demand for products and services (Indonesia, } \\
\text { Cambodia) } \\
\text { - Ministry of Health in Vietnam encouraging provincial-level } \\
\text { governments to support masons in running supply shops to } \\
\text { help meet demand in rural, remote locations }\end{array}$ \\
\hline $\begin{array}{l}\text { Capacity building/ training (formal or } \\
\text { informal e.g. peer-to-peer learning) }\end{array}$ & $\begin{array}{l}\text { - The Indonesian District Department of Small to Medium } \\
\text { Enterprises [SMEs] and Cooperatives and the District } \\
\text { Department of Mining and Industry providing capacity-building } \\
\text { support to small businesses } \\
\text { - Vietnam Ministry of Health encouraging provincial } \\
\text { governments to offer Training of Trainer courses on sanitation } \\
\text { marketing } \\
\text { - Cambodian Provincial Department of Industry and } \\
\text { Handicrafts providing technical, financial, and administrative } \\
\text { training to water entrepreneurs }\end{array}$ \\
\hline $\begin{array}{l}\text { Counselling, advisory services, } \\
\text { mentoring, consulting, and } \\
\text { psychosocial support }\end{array}$ & $\begin{array}{l}\text { - Local government liaising with sales agents and customers } \\
\text { (Cambodia, Vietnam) } \\
\text { - Department of SMEs and Cooperatives providing advice to } \\
\text { businesses on relevant registration processes (Indonesia) } \\
\text { - Cambodian provincial government supporting the promotion } \\
\text { of women to leadership roles in their communities (e.g. in } \\
\text { business) and encouraging women to participate in the private } \\
\text { sector and in public works }\end{array}$ \\
\hline Access to information & $\begin{array}{l}\text { - Local government officials informally providing information to } \\
\text { sanitation enterprises on (numbers and location of) } \\
\text { households that do not have toilets in their villages (Cambodia) }\end{array}$ \\
\hline Access to finance/ credit & $\begin{array}{l}\text { - Department of SMEs and Cooperatives in Indonesia helping } \\
\text { small businesses access provincial support for purchasing } \\
\text { equipment } \\
\text { - Cambodian provincial government providing credit to } \\
\text { projects supporting entrepreneurs }\end{array}$ \\
\hline Networking/ partnerships & $\begin{array}{l}\text { - In Indonesia, the Department of SMEs and Cooperatives } \\
\text { assisting with networking and marketing through expos }\end{array}$ \\
\hline
\end{tabular}




\begin{tabular}{|c|c|}
\hline & $\begin{array}{l}\text { - Peer-to-peer networking facilitated by local government in } \\
\text { Cambodia }\end{array}$ \\
\hline Quality assurance & $\begin{array}{l}\text { - Little activity at local government level, but at national level } \\
\text { Vietnam Ministry of Health working with UNICEF on certified } \\
\text { low-cost latrines } \\
\text { - Current discussions in Cambodia regarding quality assurance } \\
\text { and how to hold businesses to account }\end{array}$ \\
\hline $\begin{array}{l}\text { Product/ service development and } \\
\text { innovation }\end{array}$ & $\begin{array}{l}\text { - In Indonesia, the Department of Trade and Industry assisting } \\
\text { with some aspects of a new sanitation product design }\end{array}$ \\
\hline
\end{tabular}

Additional possible roles for local governments, also in the realm of business development support, include advocacy or political lobbying to higher levels of government, and supporting cost reduction of access to key resources (e.g. through bulk purchasing). Local government could also help to facilitate loans for sanitation-related projects, or undertake market assessments or research to support WASH enterprises. Our research did not provide evidence of local governments offering such support services.

[B]Linking demand and supply by promoting local enterprises

As noted in Table 2, local governments were active in promoting demand for water and sanitation services across Indonesia, Vietnam, and Cambodia, thereby creating a customer base for small-scale WASH enterprises. Our research in Indonesia highlighted that sanitation entrepreneurs relied on community-led total sanitation for triggering household demand for their services. For example, our research revealed that in the East Java city of Grobogan, sanitation entrepreneurs rely on local governments and NGOs to generate demand for their services. Without such demand creation, the sanitation entrepreneurs would have insufficient market demand.

In Vietnam, representatives from local governments (e.g. village health workers) and mass organizations (e.g. the Women's Union) also played roles in demand creation for sanitation services and products. We found evidence of local government, acting through the Commune Peoples' Committee (CPC), instructing local health workers and mass organization representatives to conduct household visits to promote the building of latrines and safe and hygienic sanitation practices. In the Mekong region of Vietnam, this demand creation for sanitation services also included the promotion of local masons' services, while in the northern province of Dien Bien, household visits were related to sanitation-awareness-raising only (i.e. no business promotion). Across the provinces where our research was conducted, CPCs varied in their enthusiasm for such activities and were driven by their own values and priorities, in one instance being motivated by a previous major health issue in the commune.

We found less evidence of local government-led efforts to create demand for water services, as typically water is already in high demand. However we did observe instances where local governments were active in explaining the importance of tariffs and payment for water services, including in Vietnam, where provincial governments regulate such tariffs.

\section{[B]Supporting associations of entrepreneurs}

Our research revealed that collective social enterprises, most visibly in the form of associations of sanitation entrepreneurs and of community-based water-supply organizations, were a key point of leverage and intervention in emerging WASH markets. Local governments offered some support to associations; however, these deserve greater attention given the important and influential role such organizations play. Several benefits were associated with association membership. The below list was drawn from interviews with water and sanitation entrepreneurs across our research locations: 
- peer-to-peer learning and capacity building opportunities;

- camaraderie, friendship, and a sense of group mission;

- access to information (e.g. information about latest water and sanitation technologies and products, new rules, and regulations);

- networking;

- opportunities for new experiences (e.g. travelling);

- fair competition;

- access to cheaper materials;

- access to credit;

- advocacy power for common issues shared by the association members (e.g. increase of water tariffs).

The literature also supports the notion that positive benefits arise from association membership and participation in business networks. For example, Sato (2015) describes a positive feedback loop when an enterprise participates in business networks such as associations. Higher capacity enterprises participate more in networks, and participation in networks help build the capacity of enterprises (Sato, 2015). Associations also allow for new social bonds to be created between members; they encourage norms of trust and cooperation and support new knowledge creation and innovation (Hulton et al., 2012). Associations are also said to support the overall market and help it thrive (Teckchandani, 2014).

Given the above documented benefits, it is unsurprising that such organizations are beginning to receive government support. In Indonesia for example, associations have emerged at the district and provincial levels. Associations of sanitation entrepreneurs have received support from the Department of Health for assistance in the delivery of training. Another Indonesian example is the government programme PAMSIMAS, which catalysed the creation of associations at district, provincial, and national level. These associations have a mandate to support the professionalization of community-based organisations (CBOs) managing community water supplies, whilst also acting as an organizational body to liaise between $\mathrm{CBO}$ s and local government. Local governments were found to provide support in some cases to these associations, including through office requirements, honoraria for staff, and travel stipends for monitoring $\mathrm{CBOs}$; however, the associations were also highly reliant on voluntary time and as such were operating as social endeavours rather than with an enterprise mindset. Local governments could further support these associations in Indonesia (and elsewhere) through a monitoring role to ensure the association has the support it needs and complies with relevant government policy.

In Cambodia, our research workshop involved discussions around how to support emerging sanitation enterprises, including through the potential formation of an association (or associations), at either local or national level. Such an association already exists at national level for water supply, however in the sanitation sector no such entity exists. Discussions are ongoing, and it is not clear whether local governments would be motivated or able to provide support to such associations, should they be established.

[B]Providing targeted subsidies or financing to facilitate access for the poor and disadvantaged

Across all countries, we did not find any evidence of cases where local governments alone had provided subsidies or financing through enterprises to ensure the poor and disadvantaged were reached; although, given the human right to sanitation, it could be argued that this is a critical role they should be playing. 
All cases involving the provision of subsidies or financing were led by NGOs in partnership with local governments, with a view to local governments adopting the approach following their demonstration. In one such case, in Cambodia, research participants from two different international NGOs described their implementation of a subsidy. This took the form of a time-bound voucher for the construction of a substructure of a pour-flush latrine, and was available to preidentified (through government system) poor households. The intention, if successful, was to consider how local governments could implement such an approach. It was ultimately decided that the implementation of such a subsidy system was not scalable, as it was time-intensive with high administrative costs and a high requirement for transparency (which may be challenging to achieve). In Vietnam, two other international NGOs were working together with relevant provincial government health agencies to develop low-cost models of latrines suitable for poor and disadvantaged households. Whilst it is conceivable that other local government agencies undertake such initiatives, this has not been documented in our research to date.

In relation to water supply, there were few examples of subsidies and discounts on the part of local governments, despite the trialling of such approaches by NGOs. For example, in Vietnam, one NGO demonstrated the success of output-based financing by supporting enterprises to develop specific outreach programmes to target the poor, sometimes including discounted connection fees or tariffs. In Vietnam's Tien Giang province, however, a local law was passed by the provincial government to phase out connection fees for water supply.

Local government can play an increasingly central role in ensuring equality in access to WASH services. For example, tax exemptions could be granted for latrine construction businesses and related services (e.g. sludge emptying). In addition, policies targeting poor or disadvantaged households, and the provision of more effective monitoring of coverage and of who gains access to services, are all areas where local government could lead.

[B]Setting and monitoring quality standards and accreditation of products and services Local governments can act to support (and regulate) enterprises by establishing standards for quality products and services. In Vietnam, the Ministry of Health's Vietnam Health Environment Management Agency (VIHEMA) was working with UNICEF to develop a range of certified low-cost latrines, using local materials where possible. Accompanied by guidance materials for government staff and masons, these standardized models that enterprises could build for households were recognized as locally appropriate and affordable. This enabled the enterprise to build certified models and provide households with information regarding affordable toilet types, enabling them to negotiate the various options. In a similar vein, one NGO was working with local health agencies to develop a system for certifying local masons' latrine construction services, which could then be a mechanism for promoting these certified masons in their business activities. Local governments could extend their role by setting technical standards for disability inclusion; however, we did not come across this in our research.

Discussions around quality assurance also emerged at our research workshop in Cambodia.

Members from both government and NGOs discussed how to accommodate the quality assurance of products and services for emerging enterprises, as it was agreed that this constituted a support function gap in the sanitation sector. In the water sector, in both Cambodia and Vietnam, local governments have mandated water-quality monitoring roles, which should help ensure appropriate water quality or enterprise services; however, research participants reported that such testing was typically less regular than required, and little in the way of results was communicated to households. 
[B]Developing appropriate local policy to support enterprise engagement

Enterprise development and success is highly influenced by the local policy environment. However, while there was evidence of national policy to support enterprise engagement in WASH (e.g.

Decision 131 in Vietnam, which provides a supportive policy framework to eligible rural water supply and sanitation enterprises), support for subnational governments to implement such policies was limited. Local governments were usually left to interpret national policy themselves. Furthermore, in Vietnam, subnational governments were not permitted to financially support private enterprises, which appeared at odds with national policy. In Indonesia, there was also reticence to spend government funds to directly support enterprises and it was thought more appropriate to provide support through indirect means (for example using an NGO as an intermediary).

Despite this shortcoming, we found evidence of local governments developing and implementing local policy to support enterprise engagement in the WASH sector. There were three main reasons for local governments to implement such policy: pressure to meet coverage targets; financial incentives; and opportunities for prestige and recognition. For example, local governments in Vietnam and Indonesia held concerns around meeting coverage targets; therefore, CPCs in Vietnam supported WASH enterprises that would result in increased coverage. Communes were assigned a 'status', based on criteria including access to services such as water and sanitation. This led to competition between communes, and the feelings of prestige that resulted from being awarded a high status drove some CPCs to support enterprises in increasing people's access to WASH services. CPCs had also implemented local regulations promoting safe sanitation, which in turn supported the conditions for successful sanitation enterprises. Local regulations were in place that required the builders of new houses to make a commitment to include a latrine. This regulation is an example of a CPC's ability to use formal local laws to create change, thereby enhancing the enabling environment for businesses and improving sanitation coverage.

In Indonesia, local government officials saw the benefits of sanitation entrepreneurs on improving monitoring data in their districts. Instances of local government staff concurrently taking on roles as entrepreneurs were also found in Indonesia, which revealed the dual motivation for enterprise development, i.e. for profit, and to improve coverage to meet targets.

We also found evidence of local government acting as an intermediary between an enterprise and a household to ensure the continuation of water supply. A CPC representative in Vietnam reported that they sometimes convene meetings with both parties to discuss problems regarding payments and service supply. This is an example of local government fulfilling its role in ensuring the human right to water, despite the service being provided by a private operator.

Some government policies, however, constrained the local government's ability to support WASH businesses. Limits on how financial resources could be invested was a particular constraint, which was a challenge faced by local governments in Vietnam. Government stakeholders reported that while their funds could be used to mobilize communities in matters relating to sanitation behaviour, they were not permitted to fund the training of masons to build government-approved toilets, since such masons belonged to the private sector.

[B]Challenges and constraints faced by local governments The roles described above provide examples of how local governments in this study were taking steps to support local water and sanitation businesses, for a range of reasons. Despite these examples of progress, there were a number of challenges and constraints that local governments faced in supporting the enabling environment for enterprises. These are described below. 
Firstly, there was a lack of clarity around the roles government could legitimately play in supporting private enterprise development. We found a strong perception amongst interviewees that governments should not, and could not, provide direct support to enterprises. In Indonesia, a government stakeholder reported that they therefore worked with NGOs as intermediary organizations, supporting businesses through a third party. This reflected a lack of clarity amongst government officials around regulations on how governments could legitimately support enterprises. Most government stakeholders we interviewed believed governments should leave private enterprises alone, and that they had to find their own ways to survive.

A second challenge was the limited experience of local governments in supporting WASH market systems and private sector engagement, leading to confusion on how to effectively support enterprises. In Vietnam, VIHEMA reported that they understood the market-based approach was valid, but that they have limited experience in implementing it. Vietnam has a historical legacy of state water provision. In rural areas in particular, people did not expect to pay for water, as under past systems governments built the water systems and handed them to communities to manage, which in turn set very low fees. This led to dysfunctional systems, and also environments unconducive to enterprise engagement and the user-pays principle. In Cambodia, government officials were unaware of the regulatory challenges faced by enterprises. While entrepreneurs reported constraining government policies (e.g. caps on water tariffs, insufficient communication about constructions works, and inadequate compensation policies for damage to pipes as a result of road construction), government stakeholders did not rate these to be challenges. In Cambodia, the lack of local policies and regulations to support water supply schemes also reflected the district government's inexperience in supporting private sector engagement. Interviewees reported caps on water tariffs and complicated bureaucracy, which were both unconducive to private sector participation. This highlights governments' inexperience in market-based approaches, and their misunderstanding of the challenges that entrepreneurs face with respect to government policies and regulations.

A third challenge was the sentiment amongst subnational government stakeholders that their role was predominantly related to demand creation, rather than supporting the supply side. It was therefore difficult to engage local departments of health in discussions around policy and regulations beyond their commitment to supporting demand creation. We found no evidence of successful contributions or partnerships with other local government agencies (the Department of SMEs and Cooperatives or the Department of Trade and Industry) responsible for private sector development in supporting sanitation businesses. We also found that local governments payed little attention to ensuring poor and disadvantaged households had access to WASH services. This demonstrates an area where governments are not meeting their obligations around the human right to water and sanitation.

Lastly, given the systems of decentralization of government authority in all three countries in this study, subnational governments made their own decisions on local priorities. These local governments must therefore be convinced to support the private sector, and indeed to invest in water and sanitation, against numerous competing priorities. In Vietnam, other priorities included economic development, security, electricity, education, and infrastructure. As a result, water and sanitation were often not priorities and did not receive ongoing budget or human resource allocations.

\section{[A]Implications and recommendations}

This research has highlighted that if the private sector is to play an effective role in improving WASH coverage, it is important to consider more than just supporting enterprises directly. In terms of development effectiveness, it is ultimately local governments and other actors (e.g. associations of 
enterprises) that need to ensure a conducive environment in which enterprises can play useful roles. Establishing an effective enabling environment for enterprises will support interventions beyond the timeframe of development programmes, and also prevent market-based approaches from being implemented in non-conducive, and thus unsustainable, settings.

Our research also revealed that ensuring equity in access is a key local government role, but very little evidence of local government activity in this area was observed. This is concerning, and points to the need for methods to help local governments monitor who does and doesn't have access to facilities and why, and consideration of how they could work through enterprises (and not just by providing direct subsidies) as part of their actions.

Based on our research findings, we provide a typology of three main roles (and various sub-roles) that local governments can play that can be useful in designing programmes and processes for supporting equitable environments for access to WASH. The three main categories are facilitation, oversight/regulation, and ensuring equality - all of which local governments can support, with our research providing evidence on how they may do so. Table 3 presents these categories.

[CAP]Table 3: Typology of local government roles to support equitable environments for access to WASH

\begin{tabular}{|c|c|c|}
\hline Facilitation & Oversight/ regulation & Ensuring equality \\
\hline $\begin{array}{l}\text { - Create demand and link } \\
\text { demand and supply } \\
\text { - Provide technical and } \\
\text { business training to } \\
\text { entrepreneurs } \\
\text { - Offer business development } \\
\text { support } \\
\text { - Facilitate access to finance } \\
\text { - Support associations of } \\
\text { entrepreneurs } \\
\text { - Undertake market } \\
\text { assessments } \\
\text { - Support or undertake } \\
\text { research and development } \\
\text { - Develop and disseminate } \\
\text { low-cost-model options } \\
\text { - Support loans for sanitation }\end{array}$ & $\begin{array}{l}\text { - Implement local policies and } \\
\text { laws to support enterprise } \\
\text { development } \\
\text { - Set and monitor quality } \\
\text { standards } \\
\text { - Accredit or certify products } \\
\text { and designs } \\
\text { - Accredit or certify masons or } \\
\text { sanitation businesses } \\
\text { - Provide licences and } \\
\text { registration } \\
\text { - Monitor enterprises or } \\
\text { associations of enterprises } \\
\text { - Grant tax exemptions for } \\
\text { latrine construction businesses } \\
\text { and related services such as } \\
\text { sludge emptying }\end{array}$ & $\begin{array}{l}\text { - Set poverty-targeting policies } \\
\text { for poor or disadvantaged } \\
\text { - Monitor coverage and who } \\
\text { gains access } \\
\text { - Identify who requires support } \\
\text { - Provide targeted subsidies } \\
\text { for poor and disadvantaged, or } \\
\text { facilitate access to loans and } \\
\text { finance for those in need } \\
\text { - Set technical standards for } \\
\text { disability inclusion } \\
\text { - Act as intermediary between } \\
\text { households and enterprises for } \\
\text { resolution of issues around } \\
\text { payment and complaints } \\
\text { - Implement regulations that } \\
\text { remove financial barriers to } \\
\text { access, e.g. connection fees for } \\
\text { water supply }\end{array}$ \\
\hline
\end{tabular}

\section{[A]Conclusion}

This research examined the roles played by local governments in supporting small-scale rural WASH enterprises in Vietnam, Cambodia, and Indonesia. Semi-structured interviews were conducted with rural water supply enterprises and sanitation entrepreneurs, non-governmental organizations, and government officials. Qualitative analysis of data was undertaken using a political economy lens. Our research uncovered a breadth of pertinent roles for local governments that supported small-scale WASH enterprise across the three countries. The findings demonstrate important local government roles including: providing training and business development support to enterprises; linking demand and supply by promoting local enterprises; supporting associations of entrepreneurs; providing targeted subsidies or financing to catalyse private sector engagement or to facilitate access to the poor and disadvantaged; and setting and monitoring quality standards and accreditation of products and services. We present a typology of roles for local governments across three categories: 
facilitation, oversight/regulation, and ensuring equality, which provides local governments with tangible actions to support an effective and conducive environment for WASH enterprises.

These findings inform gaps in development agency programming as regards WASH markets, in terms of working more strategically with local government actors, rather than solely directing efforts towards enterprises themselves. This study provides a way forward in progressing more systemic interventions to support WASH markets; interventions that facilitate local governments and related stakeholders to play more effective roles for greater and more equitable development outcomes.

Accepted manuscript 


\section{[REF]References}

Bos, R., Alves, D., Latorre, C., Macleod, N., Payen, G., Roaf, V. and Rouse, M. (2016) Manual of the Human Rights to Safe Drinking Water and Sanitation for Practitioners, International Water Association Report.

Davis, J. (2005) 'Private-sector participation in the water and sanitation sector', Annual Review of Environment and Resources 30:145-153 <doi.org/10.1146/annurev.energy.30.050504.144635>.

Devine, J. and Kullman, C. (2011) Introductory Guide to Sanitation Marketing, Water and Sanitation Program Scaling Up Rural Sanitation. Water and Sanitation Program, World Bank.

Gero, A., Carrard, N., Murta, J. and Willetts, J. (2014) 'Private and social enterprise roles in water, sanitation and hygiene for the poor: a systematic review', Journal of Water, Sanitation and Hygiene for Development 4(3): 331-345 <doi.org/10.2166/washdev.2014.003>.

Gero, A. and Willetts, J. (2014) 'Incentives for enterprise engagement in Vietnam', Private and social enterprise engagement in water and sanitation for the poor - Working Paper 2b, Institute for Sustainable Futures, University of Technology, Sydney.

Gero, A., T. Doan Trieu, T., Mohr, S., Rickwood, P., Halcrow, G. and Willetts, J. (2014) 'Relying on markets to address human rights: sanitation supply chain analysis in low-density settings', 37th WEDC International Conference, Hanoi, Vietnam, 2014.

Harris, D., 2013, 'Applied political economy analysis: a problem-driven framework', Overseas Development Institute (ODI), London.

Hulton, P., Barron, A. and Bryson, D. (2012) 'Cross country differences in attitudes to business associations during the 2007-2010 recession', Journal of World Business 47: 352-361

<doi.org/10.1016/j.jwb.2011.05.003>.

Mason, N., Matoso, M. and Smith, W. (2015) Private Sector and Water Supply, Sanitation and Hygiene, ODI Report, ODI, London.

Murta, J. and Willetts, J. (2014) 'Incentives for enterprise engagement in Indonesia', Private and social enterprise engagement in water and sanitation for the poor - Working Paper 2a, Institute for Sustainable Futures, University of Technology, Sydney.

Murthy, S.L. (2013) 'The human right(s) to water and sanitation: history, meaning, and the controversy over privatization', Berkeley Journal of International Law 31(1): 89-147

$<$ doi.org/10.15779/Z38665F>.

Ostrom, E., (2011) 'Background on the institutional analysis and development framework', The Policy Studies Journal 39(1): 7-27 <doi.org/10.1111/j.1541-0072.2010.00394.x>.

Sato, Y. (2013) 'Development of Small and Medium Enterprises in the ASEAN Economies', in R. Sukma and Y. Soeya (eds.), Beyond 2015: ASEAN-Japan Strategic Partnership for Democracy, Peace, and Prosperity in Southeast Asia, Japan Centre for International Exchange, Tokyo, pp. 154-181.

Sy, J., Warner, R. and Jamieson, J. (2014) Tapping the Markets: Opportunities for Domestic Investments in Water and Sanitation for the Poor, World Bank. 
Teckchandani, A. (2014) 'Do membership associations affect entrepreneurship? The effect of type, composition, and engagement', Nonprofit and Voluntary Sector Quarterly 43(2S): 84S104 S <doi.org/10.1177/0899764013502580>.

Whaley, L. and Cleaver, F. (2017) 'Can 'functionality' save the community management model of rural water supply?' Water Resources and Rural Development 9: 56-66

<doi.org/10.1016/j.wrr.2017.04.001>.

Willetts, J., Murta, J., Gero, A., Carrard, N. and Harris, D. (2015) 'Political economy influences on enterprise engagement in Indonesia, Vietnam and Timor-Leste', Water, sanitation and hygiene services beyond 2015: Improving access and sustainability - 38th WEDC International Conference, Loughborough University, UK, 2015.

Willetts, J., Murta, J., Gero, A. (2016), 'Water and sanitation entrepreneurs in Indonesia, Vietnam and Timor-Leste: Traits, drivers and challenges', Enterprise in WASH - Working Paper 4, Institute for Sustainable Futures, University of Technology Sydney.

Willetts, J., Gero, A., Susamto., A.A., Sanjaya, R., Trieu, T.D., Murta, J. and Carrard, N. (2017) 'Sanitation value chains in low density settings in Indonesia and Vietnam: impetus for a rethink to achieve pro-poor outcomes', Journal of Water Sanitation and Hygiene for Development 7(3): 445454 <doi.org/10.2166/washdev.2017.141>.

Willetts, J. and Powell, B. (2017) 'Financing sanitation: Finding a middle path to reach the poor Learning Brief from the East Asia Regional Learning Event', Civil Society Water, Sanitation and Hygiene (WASH) Fund. 